\title{
Caracterização microestrutural das ligas AA7004 e AA7075 tixoforjadas em prensa excêntrica
}

\author{
Microstructural characterization of the \\ AA7004 and AA7075 thixoforging alloys \\ in an eccentric press
}

\begin{abstract}
${ }^{1}$ Instituto Federal de Educação, Ciência e Tecnologia de São Paulo - IFSP, CEP: 12929-600, Bragança Paulista, São Paulo, Brasil.

${ }^{2}$ Departamento de Engenharia de Manufatura e Materiais, Faculdade de Engenharia Mecânica, Universidade Estadual de Campinas - UNICAMP, CEP: 13083-860, Campinas, São Paulo, Brasil.

e-mail: torres@ifsp.edu.br, torres@fem.unicamp.br, zoqui@fem.unicamp.br
\end{abstract}

\section{RESUMO}

Este trabalho tem como objetivo analisar o processo de tixoforjamento em prensa excêntrica das ligas aeronáuticas AA7004 e AA7075 e compreender o comportamento do material semissólido durante o preenchimento da matriz através de análises microestruturais. As ligas foram submetidas a tratamentos térmicos de globularização pelo tempo de $210 \mathrm{~s}$ e fração líquida de $55 \%$ e na sequência tixoforjadas. As temperaturas de trabalho foram determinadas via ensaios de DSC (differential scanning calorimetry). O tratamento térmico de globularização tem como objetivo efetuar a globularização parcial ou total das ligas, permitindo analisar a evolução microestrutural. A força máxima aplicada no ensaio de tixoforjamento foi de aproximadamente 500 $\mathrm{kg}$, sendo que a capacidade da prensa excêntrica segundo seu fabricante é de 25 toneladas, demonstrando que a carga utilizada para a realização dos ensaios foi irrisória em comparação com a capacidade do equipamento. $\mathrm{O}$ produto final apresentou total preenchimento da matriz e qualidade dimensional. A região localizada no centro da peça, onde ocorreu a maior deformação apresentou grãos deformados e menores em relação às outras regiões, a saber, a liga AA7004 apresentou tamanho de grãos de $142 \mu \mathrm{m}$ e a liga AA7075 apresentou tamanho de grãos de $105 \mu \mathrm{m}$.

Palavras-chave: Tixoforjamento, material semissólido, prensa excêntrica, AA7004, AA7075.

\section{ABSTRACT}

The aim of this work was to analyze the thixoforging process in an eccentric press of the AA7004 and AA7075 aeronautical alloys and to understand the behavior of the semisolid material during the filling of the die through microstructural analysis. The alloys were subjected to globularization heat treatments for 210 seconds and liquid fraction of 55\% and in the sequence thixoforged. Working temperatures were determined via DSC tests (differential scanning calorimetry). The globularization heat treatments aim to effect the partial or total globularization of the alloys, allowing the analysis of microstructural evolution. The maximum force applied in the thixoforging process was approximately $500 \mathrm{~kg}$, and the capacity of the eccentric press according to its manufacturer is 25 tons, demonstrating that the force used to perform the tests was negligible compared of the capacity of the equipment. The thixoforged final product presented total filling of the die and dimensional quality. The part in the center of the final product, where the biggest deformation occurred, presented deformed and smaller grains in relation to the other parts, namely the AA7004 alloy presented a grain size of $142 \mu \mathrm{m}$ and the AA7075 alloy presented a grain size of $105 \mu \mathrm{m}$.

Keywords: Thixoforging, semi-solid material, eccentric press, AA7004, AA7075.

\section{INTRODUÇÃO}

A conformação semissólida, ou tixoconformação, nada mais é do que o processamento de ligas metálicas no estado de coexistência de fase sólida e fase líquida. Estes materiais semissólidos apresentam características 
estruturais particulares, diferente dos processos convencionais de fundição e conformação, seja no aspecto de processamento como no aspecto morfológico; o forjamento no estado semissólido, ou tixoforjamento ocorre quando um material no estado semissólido apresenta uma estrutura globular devido a um tratamento térmico. Nessas condições, o material é conformado sobre pressão em uma matriz de forjamento, tomando sua forma final [1, 2]. São inúmeras as vantagens da utilização deste processo, a saber: menor consumo de energia, redução de etapas de produção, aumento da produtividade, aumento da vida útil de matrizes, obtenção de peças com excelente acabamento superficial e produção near-net-shape [3, 4, 5, 6, 7].

A indústria automobilística tem se mostrado como principal patrocinadora para o desenvolvimento de novos processos para a produção de peças com materiais no estado semissólido. A utilização do alumínio nos automóveis, primeiramente sob a forma de fundido, aumentou drasticamente devido à necessidade de se produzir partes com alta resistência mecânica, alta confiabilidade e baixo peso. Assim sendo, é neste nicho de mercado que se torna importante o desenvolvimento da tecnologia de produção de peças no estado semissólido [8]. As ligas de alumínio são as de maior aplicação nos processos que envolvem materiais semissólidos, no entanto, as ligas alumínio-silício apresentam destaque quando comparadas com outras, ocupando $95 \%$ de todas as aplicações, enquanto que todas as outras ligas somadas representam somente 5\% [9]. Nas últimas décadas, ocorreram avanços significativos nos estudos sobre o processo de tixoconformação, objetivando a melhor forma de produção da matéria-prima e consequentemente a obtenção de microestruturas refinadas e homogêneas, com bom comportamento reológico e com boas propriedades mecânicas [10, 11, 12, 13, 14]. Portanto, as razões que fundamentam este trabalho e, ao mesmo tempo, apresentam as justificativas do trabalho podem ser compreendidas segundo alguns aspectos, a saber: este estudo tem como objetivo contribuir para o desenvolvimento do processo de tixoconformação, além da utilização de outras famílias de ligas de alumínio, contribuindo para o desenvolvimento de novas matérias-primas. As ligas tixoforjadas foram caracterizadas microestruturalmente, através de metalografia convencional (escala de cinza) e metalografia colorida contribuindo assim para a melhor compreensão do comportamento do material semissólido.

\section{MATERIAIS E MÉTODOS}

É importante notar que a metodologia adotada, segue a mesma de trabalhos anteriores $[15,16,17]$ para o tixoforjamento em prensa excêntrica, ou seja, perfazendo a caracterização das temperaturas de trabalho, como também a caracterização microestrutural para a compreensão do seu comportamento semissólido durante o processo de tixoforjamento.

\subsection{Matéria-prima}

Para o desenvolvimento deste trabalho foram utilizadas as ligas comerciais de alumínio AA7004 e AA7075 produzidas via lingotamento contínuo convencional pela empresa ALCOA Alumínio S.A. Estas ligas apresentam como componente principal, além do alumínio, o zinco; suas composições químicas em peso podem ser vistas na Tabela 1. Alguns fatores favoráveis para a escolha destas ligas são: faixa de temperatura entre as linhas solidus e liquidus razoavelmente ampla, facilitando o controle dos parâmetros operacionais do processo de tixoforjamento (a) e ampla utilização comercial, principalmente na indústria aeronáutica (b).

Tabela 1: Composição química em peso (wt\%) das ligas AA7004 e AA7075 conforme fabricante.

\begin{tabular}{cccccccc}
\hline LIGA & Zn & Mg & Cu & Fe & Si & Mn & Al \\
\hline AA7004 & 5,8 & 1,5 & 0,1 & 0,4 & 0,3 & 0,5 & Balanço \\
\hline AA7075 & 6,2 & 2,0 & 1,7 & 0,5 & 0,4 & 0,1 & Balanço \\
\hline
\end{tabular}

\subsection{Caracterizações das temperaturas de trabalho}

A determinação do intervalo de temperatura entre as linhas solidus e liquidus, zona de equilíbrio entre as fases sólida e líquida, é essencial para a obtenção da pasta semissólida com estrutura globular utilizada nos processos de tixoconformação. As temperaturas de trabalho foram determinadas via ensaios de DSC (differential scanning calorimetry). As análises via DSC foram realizadas com auxílio de um equipamento de análise térmica NETZSCH modelo STA 409C, utilizando-se amostras com massa de $100 \mathrm{mg}$, com taxa de aquecimento de $5{ }^{\circ} \mathrm{C} / \mathrm{min}$ até $700{ }^{\circ} \mathrm{C}$ e resfriamento até temperatura ambiente com taxa de resfriamento análoga. Fornecendo as temperaturas solidus e liquidus das ligas como também as temperaturas de trabalho correspondentes à fração líquida de 55\%, conforme pode ser vista na Figura 1, já na Tabela 2 tem-se um resumo de todas as temperaturas encontradas. LIU et al. [18] propôs alguns critérios termodinâmicos para classificar 
uma liga como sendo propicia à matéria-prima para tixoconformação e entre estes critérios espera-se que a faixa de temperatura para a sua solidificação completa $(\Delta \mathrm{T})$ seja inferior a $130{ }^{\circ} \mathrm{C}$ e como pode ser visto, ambas as ligas apresentaram este critério.
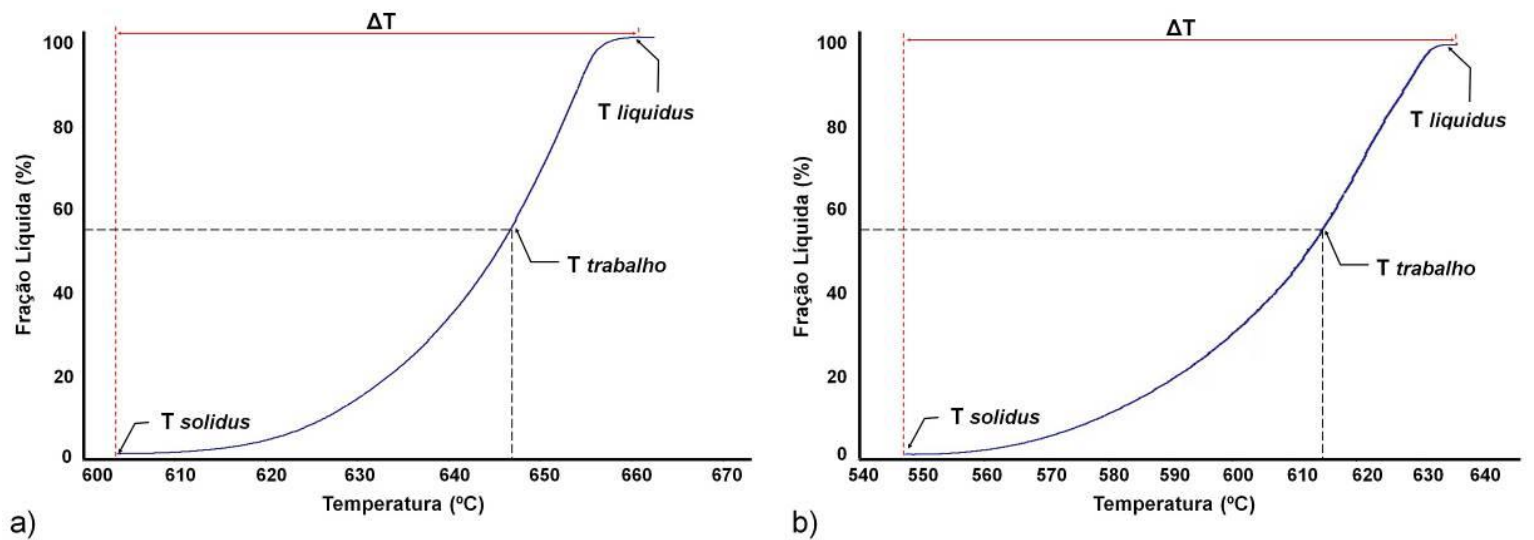

Figura 1: Curva da fração líquida versus temperatura obtida via ensaio de DSC para as ligas: AA7004 (a) e AA7075 (b).

Tabela 2: Resumo das temperaturas obtidas via ensaios de DSC: Temperatura solidus, Temperatura liquidus, Faixa de solidificação $(\Delta \mathrm{T})$ e Temperatura de trabalho [19].

\begin{tabular}{ccccc}
\hline LIGA & $\mathbf{T}$ solidus $\left[{ }^{\circ} \mathbf{C}\right]$ & T liquidus $\left[{ }^{\circ} \mathbf{C}\right]$ & $\Delta \mathbf{T}\left[{ }^{\circ} \mathbf{C}\right]$ & $\mathbf{T}$ trabalho $\left[{ }^{\circ} \mathbf{C}\right]$ \\
\hline AA7004 & 603 & 662 & 59 & 647 \\
\hline $\mathbf{A A 7 0 7 5}$ & 548 & 636 & 88 & 614 \\
\hline
\end{tabular}

\subsection{Tixoforjamento em prensa excêntrica}

Os equipamentos utilizados na realização dos ensaios foram uma prensa excêntrica com capacidade de 25 toneladas e instrumentada, forno resistivo utilizado para o aquecimento da matéria-prima, matriz confeccionada com aço AISI H13, resistência elétrica utilizada para o aquecimento da matriz (aproximadamente $200{ }^{\circ} \mathrm{C}$ ) e sistema de aquisição de dados, conforme visto na Figura 2. O produto tixoforjado foi projetado para possuir raios e chanfros de maneira a facilitar o escoamento do material dentro da matriz, assim como sua extração. A prensa excêntrica foi instrumentada para permitir o monitoramento das forças durante o processo de tixoforjamento. Uma célula de carga tipo S de 1-S40 / 25T com uma sensibilidade de 3mV/V, precisão de $0,05 \%$ e máximo de força de 25 toneladas foi ajustada ao êmbolo da prensa juntamente com um micro-Epsilon LVDT VIP - sensor de deslocamento indutivo sem desgaste 200-ZA-2-SR7-I (linearidade \pm 0,2\%). Ambos os sinais foram capturados por um National Instruments USB 6210, utilizando o software Labview ${ }^{\circledR}$ para adquirir e registrar dados de força, tempo e posição (em N, ms e m, respectivamente) a uma taxa de 5000 leituras por segundo [20].

As operações que envolvem o processo de tixoforjamento são compostas basicamente de dois estágios: o aquecimento (ou reaquecimento) da matéria-prima e a conformação da peça. Portanto, o procedimento estabelecido para a realização do ensaio de tixoforjamento consistiu no aquecimento dos corpos de prova bem como no aquecimento da matriz pela resistência elétrica. Os corpos de prova eram inseridos no forno resistivo com um termopar tipo K, Cromel Alumel, fixado em seu interior. Após alcançar a temperatura relativa à fração líquida de $55 \%$ e o tempo de globularização de $210 \mathrm{~s}$, o corpo de prova era transferido para a matriz, retirando o termopar de sua extremidade. Posicionado o corpo de prova dentro da matriz, era acionado o sistema de aquisição de dados e o acionamento da prensa. As dimensões dos corpos de prova utilizados foram de $145 \mathrm{~mm}$ de comprimento e $27,5 \mathrm{~mm}$ de diâmetro e com furo de 1,6 $\mathrm{mm}$ de diâmetro na metade de seu diâmetro para ser inserido o termopar. Segundo ZOQUI et al. [15], quando o material é comprimido entre matrizes para o tixoforjamento, a fluidez é menor ao longo do comprimento do que em relação a sua largura, assim, para um bom preenchimento da matriz é necessário que o corpo de prova possua suas dimensões finais próximas à da matriz, principalmente em relação ao seu comprimento; obtendo o produto final com $150 \mathrm{~mm}$ de comprimento, conforme visto na Figura 3. 


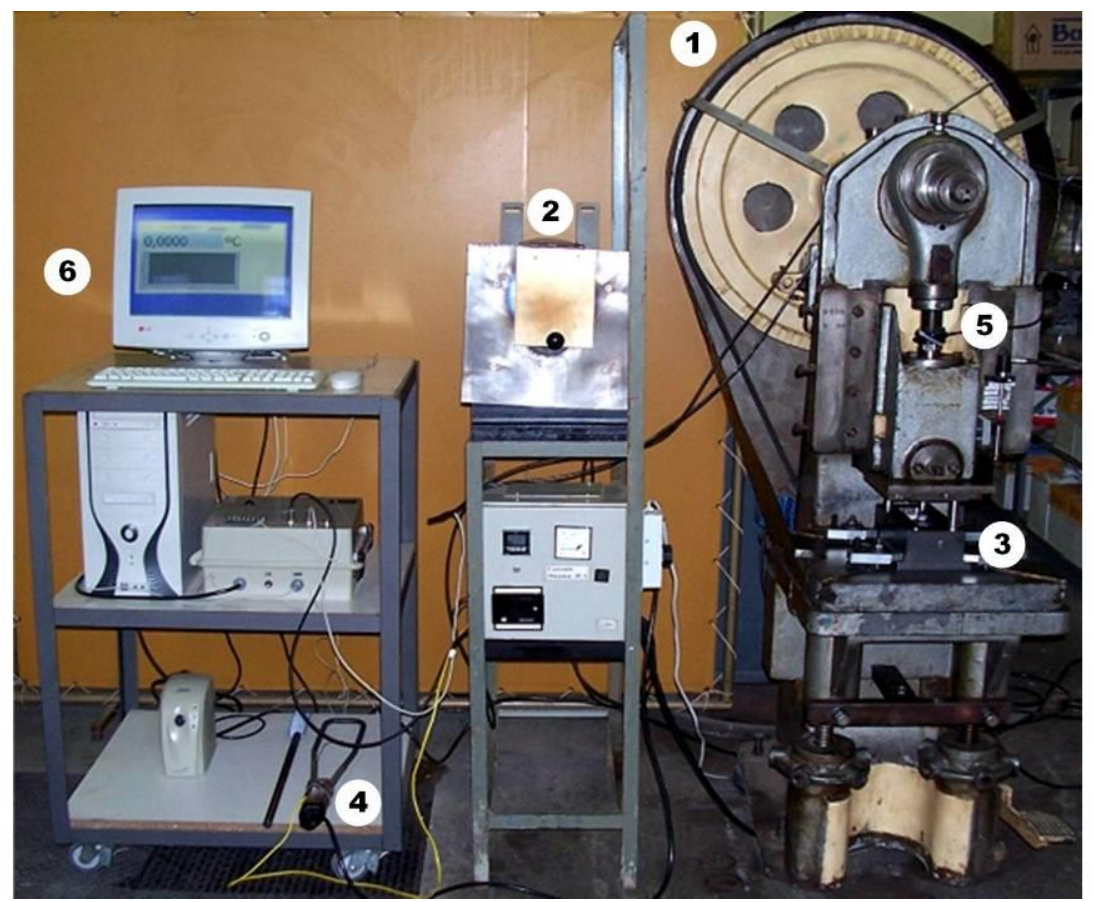

Figura 2: Conjunto de equipamentos utilizados na realização dos ensaios de tixoforjamento: prensa excêntrica (1), forno resistivo (2), matriz (3), resistência elétrica (4), célula de carga e sensor de deslocamento (5) e sistema de aquisição de dados (6).
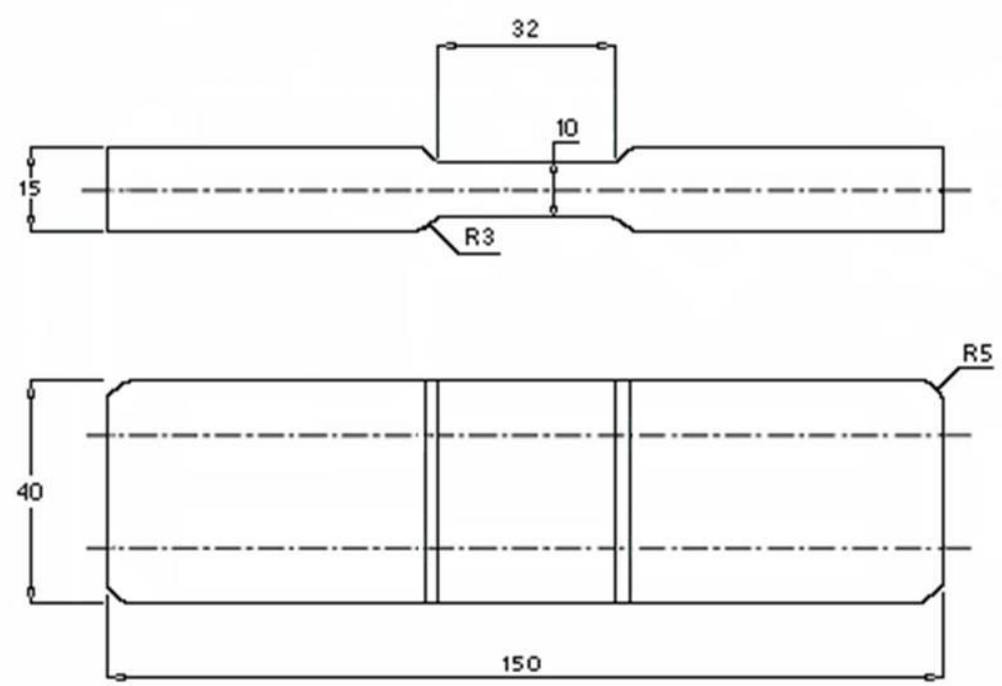

Figura 3: Dimensões finais das peças tixoforjadas.

\subsection{Caracterização microestrutural}

A caracterização microestrutural, ou seja, metalografia convencional e metalografia colorida visa revelar a estrutura do material. Assim, as amostras foram lixadas em lixa d'água de 220, 320, 400, 600, 800, 1200 e 1500 e polidas com pasta de diamante de $6 \mu \mathrm{m}$ para um polimento grosseiro e com pasta de diamante de 1 $\mu \mathrm{m}$ para o polimento de acabamento. Após o polimento, as amostras foram atacadas com reagente Keller $(2,5$ $\mathrm{ml} \mathrm{HNO}_{3}, 1,5 \mathrm{ml} \mathrm{HCl}, 1 \mathrm{ml} \mathrm{HF} \mathrm{e} 95 \mathrm{ml} \mathrm{H}_{2} \mathrm{O}$ ) por um tempo de $10 \mathrm{~s}$ visando revelar seus glóbulos primários via metalografia convencional. Para a aquisição das imagens foi utilizado um microscópio óptico Leica DM ILM. Para a caracterização microestrutural via metalografia colorida, as mesmas amostras passaram na sequência por um ataque eletrolítico com deposição de $\mathrm{HBF}_{4}$ (ácido fluorbórico) em solução 6,0\% e tensão de $20 \mathrm{~V}$ por cerca de $90 \mathrm{~s}$ sob agitação moderada e constante. Para as medições do tamanho de glóbulos primários e de grãos empregou-se o Método dos Interceptos de Heyn, regido pela norma ASTM E112 [21]. As contagens foram realizadas em cinco diferentes campos de cada micrografia, sendo que para cada amostra fo- 
ram empregadas cinco imagens de diferentes seções, totalizando vinte e cinco contagens de glóbulos primários e grãos para cada amostra. As regiões caracterizadas microestruturalmente podem ser vistas na Figura 4(a).

\section{RESULTADOS E DISCUSSÃO}

Durante a execução dos ensaios de tixoforjamento foram registrados os valores referentes à força máxima de fechamento para a condição estabelecida, ou seja, 55\% de fração líquida e tempo de tratamento de $210 \mathrm{~s}$. A força máxima foi de aproximadamente $500 \mathrm{~kg}$ para ambas as ligas, sendo que a capacidade da prensa excêntrica segundo seu fabricante é de 25 toneladas, pode-se dizer que a carga utilizada para a realização dos ensaios foi irrisória em comparação com a capacidade da prensa. ZOQUI et al. [15] obteve resultados de força máxima de fechamento das matrizes com ligas Al-Si-Mg superiores em relação à este trabalho, com valores em torno de 12 toneladas. O produto tixoforjado pode ser visto na Figura 4(a), nota-se uma boa conformabilidade do produto, preenchendo toda a matriz e reproduzindo sua geometria. $\mathrm{O}$ bom preenchimento e reprodução da geometria devem-se em especial pelo fato de estar trabalhando com a fração líquida de 55\%, pois apresenta uma menor quantidade de fase sólida no material, contribuindo assim para uma melhor qualidade dimensional do produto.

Com o objetivo de se compreender melhor o comportamento do material semissólido durante o preenchimento da matriz foram realizadas análises microestruturais, metalografia convencional para a visualização dos glóbulos primários como também a metalografia colorida para a visualização dos grãos, em diferentes regiões do produto conforme pode ser vista na Figura 4(a). De acordo com conceitos metalúrgicos, cada grão se difere do outro devido a diferentes orientações cristalográficas, assim, com luz polarizada, grãos diferentes apresentam colorações diferentes facilitando a sua identificação, já para o glóbulo não é tão fácil sua identificação devido às interconexões existentes na microestrutura.

Observando as metalografias coloridas, tem-se que o sistema de análise de imagens utilizando luz polarizada se mostrou eficiente para se determinar os tamanhos de grãos das ligas estudadas. Analisando qualitativamente as microestruturas das ligas da Figura 4, principalmente a região localizada na extremidade da peça (região A), nota-se a morfologia globular para a liga AA7075 e morfologia globular-irregular para a liga AA7004, ou seja, glóbulos bastantes esferoidizados para a condição de estudo, sendo que os principais mecanismos para a obtenção desta microestrutura globular são os fenômenos de ostwald ripening e coalescência, ambos dependentes do tempo de permanência da liga à temperatura de tratamento térmico [22, 23, 24, 25]. Quanto menor o tamanho da microestrutura a ser submetida ao tratamento térmico de reaquecimento, melhor será o efeito de globularização, exemplo disto é a liga AA7075 apresentando uma microestrutura mais globular quando comparada com a liga AA7004.

ZOQUI et al. [15] e LOURENÇATO [16] também observaram a presença de microestruturas diferentes para cada região da peça (produto final), apresentando variações de tamanho de glóbulos / grãos, sendo identificáveis três áreas principais: uma área localizada na extremidade da peça, contendo glóbulos / grãos com estrutura globular e com maior tamanho (região A), a área de curvatura da peça contendo glóbulos / grãos globulares e deformados (região B) e por fim a área localizada no centro da peça, onde houve a maior deformação, constituída de glóbulos / grãos totalmente deformados e com tamanhos menores (região C), como pode ser visto na Tabela 3. A liga AA7075 apresentou na região C o tamanho de glóbulo primário superior às outras áreas, este fato pode ser explicado devido à forte deformação sofrida nesta região, fazendo com que os contornos de grãos praticamente desaparecessem, sendo assim fundamental a análise via metalografia colorida para uma melhor caracterização. Observa-se que as regiões próximas da extremidade da peça apresentam microestrutura globular típica dos materiais no estado semissólido, sem nenhuma aparência de deformação. Pode-se observar que ocorreu a presença de líquido nesta região (na análise o material já estava sólido), resultando em maior quantidade de segunda fase no sólido tixoforjado. Esta morfologia decorre do fato de que os glóbulos primários / grãos que constituem esta parte da peça são aqueles que, no corpo de prova, se encontravam na frente de escoamento, isto é, o primeiro material a penetrar na cavidade da matriz. Durante a deformação, estes glóbulos primários / grãos são transportados conjuntamente com o líquido sem que sofram grande deformação, resultando em uma região com estrutura globular. Todas as peças apresentaram a maior deformação justamente no centro do produto. Essa maior deformação já era esperada, uma vez que a geometria lhe conferia esse resultado. 

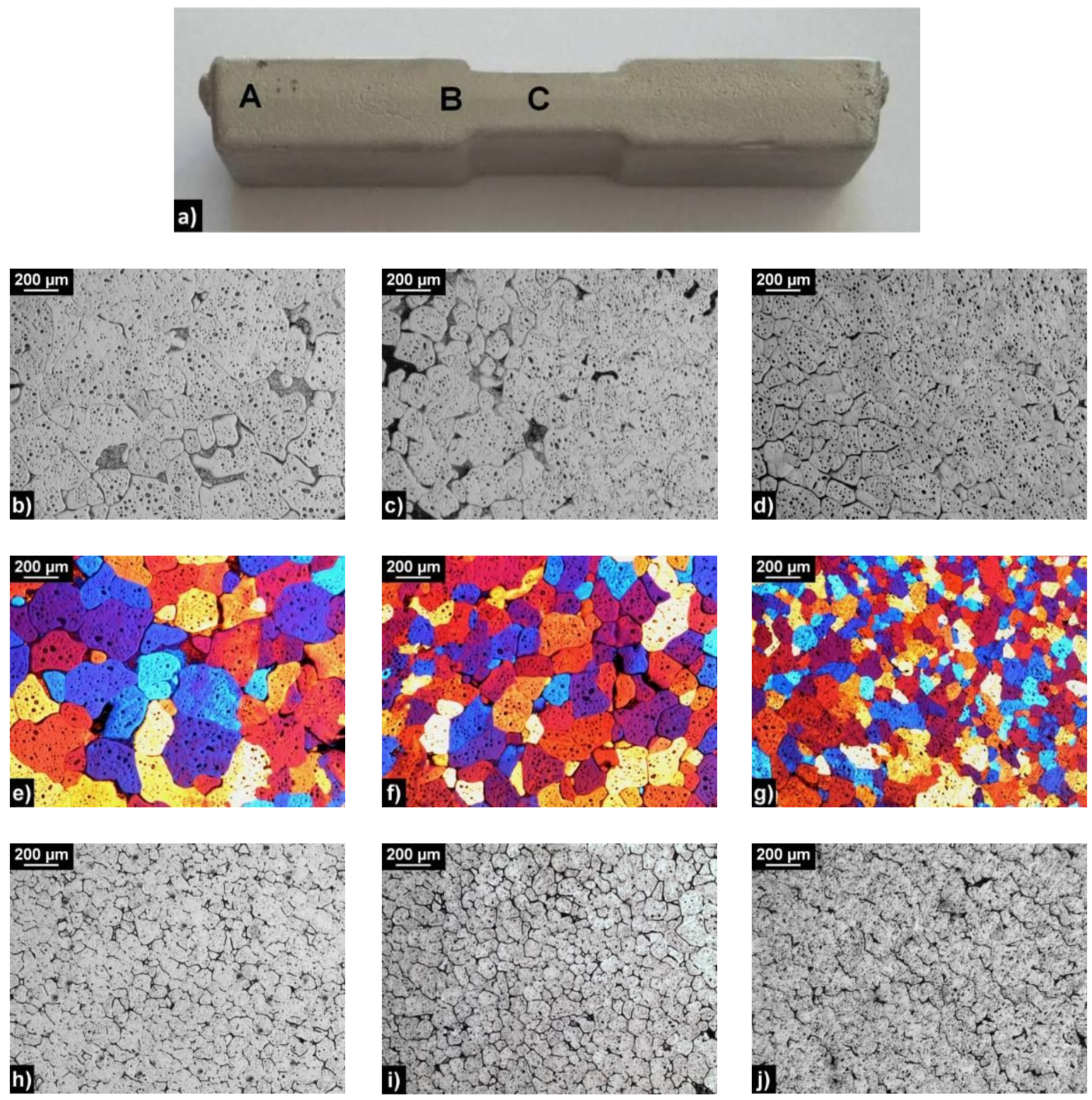

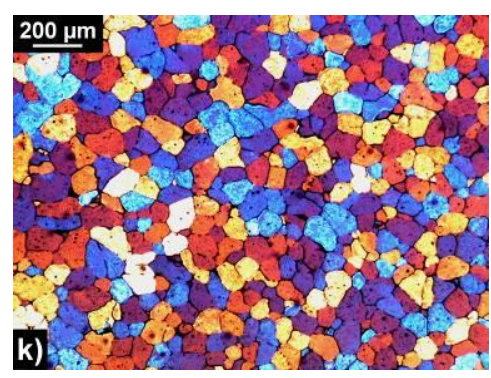

região A

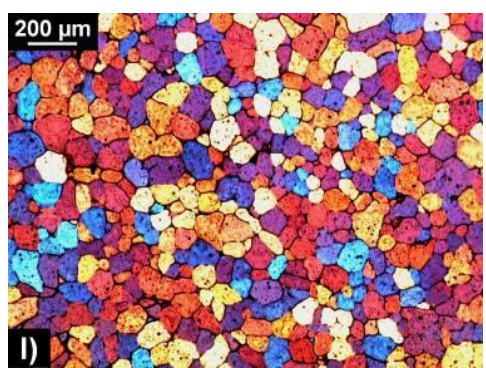

região B

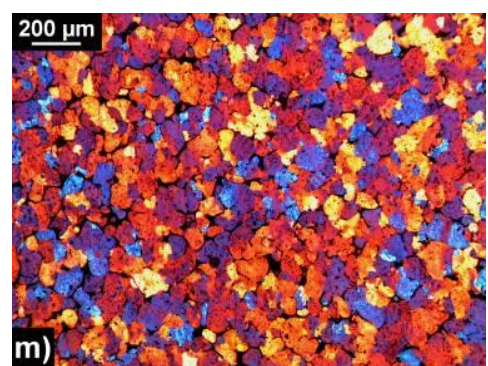

região C

Figura 4: Produto final tixoforjado (a); micrografias das ligas tixoforjadas AA7004 (b, c, d, e, f, g) e AA7075 (h, i, j, k, l, m) nas três regiões distintas do produto: extremidade da peça (região A), curvatura da peça (região B) e área central da peça (região C). 
Tabela 3: Caracterização microestrutural das ligas: tamanho médio de glóbulo primário e tamanho médio de grão.

\begin{tabular}{cccc}
\hline LIGA & REGIÃO & GLÓBULO PRIMÁRIO $[\mu \mathrm{m}]$ & GRÃO $[\mu \mathrm{m}]$ \\
\hline \multirow{2}{*}{ AA7004 } & A & $189 \pm 25$ & $267 \pm 11$ \\
\cline { 2 - 4 } & B & $188 \pm 26$ & $206 \pm 43$ \\
\cline { 2 - 4 } AA7075 & C & $129 \pm 31$ & $142 \pm 12$ \\
\hline & A & $79 \pm 6$ & $123 \pm 22$ \\
\hline & B & $78 \pm 5$ & $118 \pm 23$ \\
\hline
\end{tabular}

A deformação de materiais no estado semissólido ocorre por intermédio de algumas etapas: escorregamento da fase sólida em suspensão no líquido, expulsão do líquido para frente do escoamento, deformação dos grãos e consequentemente compactação da fase sólida [26]. Portanto, a partir destes mecanismos pode-se propor um modelo esquemático do preenchimento da matriz como visto na Figura 5. Para tanto, foram levados em consideração os resultados apresentados anteriormente quanto à evolução morfológica dos materiais. Estas observações permitem dividir em três etapas o processo de tixoforjamento: recalque, cisalhamento e compactação da fase sólida.

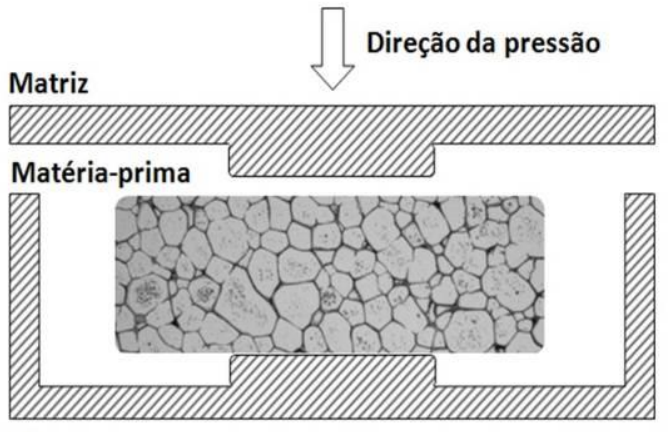

a)

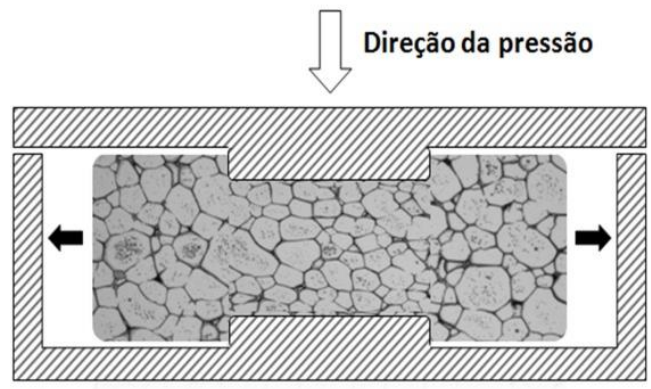

c)

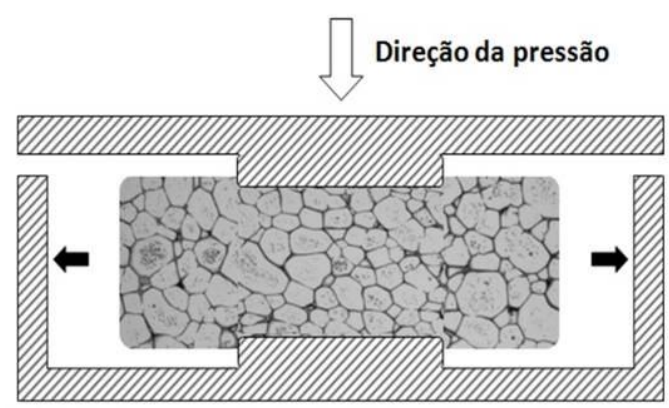

b)

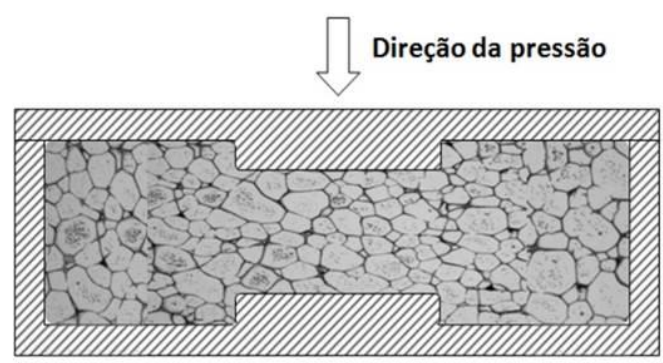

d)

Figura 5: Modelo esquemático do preenchimento da matriz no tixoforjamento: início (a), recalque (b), cisalhamento (c) e compactação (d); adaptado de ROVIRA [26].

i. Recalque: após o início do processo, observa-se na Figura 5(b) que as tensões de cisalhamento geradas pela força aplicada (fase inicial da deformação) produzem recalque na base do corpo de prova com o deslocamento dos glóbulos primários, a presença de líquido contornando os glóbulos primários / grãos reduz a resistência da deformação sendo que esta resistência diminui ainda com a temperatura semissólida, dada a maior quantidade de líquido presente. Nesta fase já há provavelmente a separação sólido / líquido com o líquido sendo rejeitado para frente do escoamento.

ii. Cisalhamento: na Figura 5(c) começa a ocorrer o preenchimento da matriz devido ao escoamento 
do material. O movimento relativo dos glóbulos primários / grãos sob o efeito das tensões de cisalhamento geradas pela força aplicada no material acarreta em seu rompimento. À medida que ocorre a conformação da peça, um maior número de contornos de grãos entram em contato, como resultado da rejeição de líquido para frente do escoamento, o que, unido ao atrito gerado pelo escoamento do material em contato com as paredes do molde, há o aumento da resistência na conformação. Neste momento, o material tentará escoar pelo caminho mais livre.

iii. Compactação: na Figura 5(d) observa-se o último estágio do processo de tixoforjamento, onde ocorre a compactação mais intensa da estrutura, ou seja, o líquido guiado por gradientes de pressão é rejeitado para as extremidades da peça gerando assim uma região com muito líquido e na área central da peça praticamente não havendo presença de líquido. E como a área central da peça sofre uma alta deformação até a fase final de compactação, tem-se como resultado grãos totalmente deformados.

\section{CONCLUSÕES}

A partir dos estudos realizados para a melhor compreensão do comportamento dos materiais semissólidos AA7004 e AA7075 no processo de tixoforjamento em prensa excêntrica tem-se que os materiais passam pelas etapas de escorregamento da fase sólida em suspensão no líquido, da expulsão do líquido para frente do escoamento, da deformação dos grãos e compactação da fase sólida, formando assim três regiões microestruturais distintas no produto final, consequentemente distintos valores de tamanho de glóbulos primários / grãos. A matriz foi preenchida em sua totalidade reproduzindo sua geometria, devido principalmente pela fração líquida de 55\%, ou seja, apresentando uma menor quantidade de fase sólida no material, contribuindo para um melhor escoamento do material e consequentemente uma força máxima de fechamento da matriz muito pequena, ou seja, de aproximadamente $500 \mathrm{~kg}$.

\section{AGRADECIMENTOS}

Os autores agradecem a empresa ALCOA Alumínio S.A. pela doação da matéria-prima e a CAPES (Coordenação de Aperfeiçoamento de Pessoal de Nível Superior) por seu apoio financeiro. Gostaríamos também de agradecer à FEM/UNICAMP - Faculdade de Engenharia Mecânica da Universidade Estadual de Campinas e ao IFSP - Instituto Federal de Educação, Ciência e Tecnologia de São Paulo, campus Bragança Paulista.

\section{BIBLIOGRAFIA}

[1] SPENCER, D.B., MEHRABIAN, R., FLEMINGS, M.C., "Rheological behavior of Sn-15\%Pb in the crystallization range”, Metallurgical Transactions, v. 3, pp. 1925-1932, 1972.

[2] FLEMINGS, M.C., RIEK, R.G., YOUNG, K.P., "Rheocasting processes”, AFS International Cast Metals Journal, v. 1, pp. 11-22, 1976.

[3] FLEMINGS, M.C., "Behavior of metal alloys in the semi-solid state", Metallurgical Transactions A, v. 22, pp. 957-981, 1991.

[4] BROWN, S.B., FLEMINGS, M.C., "Net shape forming via semi-solid processing", Advanced Materials \& Processes, v. 1, pp. 36-40, 1993.

[5] KAPRANOS, P., WARD, P.J., ATKINSON, H.V., "Near net shaping by semi-solid metal processing", Materials and Design, v. 21, pp. 387-394, 2000.

[6] WANG, P., CUI, J.Z., "Nondendritic microstructure of A356 alloy obtained by the nearby liquidus casting and thixoformed properties", Acta Metallurgica, v. 38, pp. 952-955, 2002.

[7] ATKINSON, H.V., "Modeling the semi-solid processing of metallic alloys", Progress in Materials Science, v. 50, pp. 341-412, 2005.

[8] FIGUEREDO, A., "Science and technology of semi-solid metal processing”, Worcester Polytechnic Institute, Worcester, USA, 2001.

[9] CHIARMETTA, G., "Why thixo?", In: Proceedings of the $6^{\text {th }}$ international conference on the semi-solid processing of alloys and composites, pp. 15-21, Turin, September, 2000.

[10] CAMPO, K.N., ZOQUI, E.J., "Thixoforming of an Ecaped aluminum A356 alloy: microstructure evolution, rheological behavior, and mechanical properties", Metallurgical and Materials Transactions A: Physical Metallurgy and Materials Science, v. 47, n. 4, pp. 1792-1802, 2016. 
[11] TORRES, L.V., TORRES, L.F., ZOQUI, E.J., "Electromagnetic stirring versus ECAP: morphological comparison of Al-Si-Cu alloys to make the microstructural refinement for use in SSM processing", Advances in Materials Science and Engineering, v. 2016, Article ID 9789061, 2016.

[12] PRONI, C.T.W., TORRES, L.V., HAGHAYEGHI, R., ZOQUI, E.J., "ECAP: an alternative route for producing AlSiCu for use in SSM processing”, Materials Characterization, v. 118, pp. 252-262, 2016.

[13] ZOQUI, E.J., BENATI, D.M., PRONI, C.T.W., TORRES, L.V., "Thermodynamic evaluation of the thixoformability of Al-Si alloys", Calphad: Computer Coupling of Phase Diagrams and Thermochemistry, v. 52, pp. 98-109, 2016.

[14] TORRES, L.V., TORRES, L.F., ZOQUI, E.J., "Microstructural characterization of the A356 alloy in different processing routes used in the thixoforming process", Revista Matéria, v. 22, n. 4, 2017.

[15] ZOQUI, E.J., LOURENÇATO, L.A., BENATI, D.M., "Thixoforming of aluminium-silicon alloys in a mechanical eccentric press", Solid State Phenomena, v. 141-143, pp. 517-522, 2008.

[16] LOURENÇATO, L.A., Tixoformabilidade e tixoforjamento de ligas Al-Xwt $\% \mathrm{Si}-0,5 \mathrm{wt} \% \mathrm{Mg}$ em prensa excêntrica com matriz aberta. Tese de D.Sc., FEM/UNICAMP, Campinas, SP, Brasil, 2008.

[17] TORRES, L.V., Tixoconformação de novas ligas Al-Si-Cu, Tese de D.Sc., FEM/UNICAMP, Campinas, SP, Brasil, 2013.

[18] LIU D., ATKINSON H.V., JONES H., "Thermodynamic prediction of thixoformability in alloys based on the Al-Si-Cu and Al-Si-Cu-Mg systems", Acta Materialia, v. 53, n.14, pp. 3807-3819, 2005.

[19] ZOQUI, E.J., TORRES, L.V., "Evaluation of the thixoformability of AA7004 and AA7075 alloys", Materials Research, v. 13, n. 3, pp. 305-318, 2010.

[20] NADAL, R.L., ROCA, A.S., FALS H.D.C., ZOQUI E.J., "Mechanical properties of thixoformed hypoeutectic gray cast iron", Journal of Materials Processing Technology, v. 226, pp. 146-156, 2015.

[21] AMERICAN SOCIETY FOR TESTING AND MATERIALS, ASTM. E112: Standard test methods for determining average grain size, West Conshohocken, 1996.

[22] GENDA, G., YUYON, C., GEING, A., "Mechanism of coarsening of dendrite during solidification", In: Proceedings of the solidification processing conference, pp. 416-419, Sheffield, 1987.

[23] KIRKWOOD, M.C., "Semi-solid metal processing”, International Materials Reviews, v. 39, pp. 173$189,1994$.

[24] KATTAMIS, T.Z., COUGHIN, J.L., FLEMINGS, M.C., "Influence of coarsening on dendritic arm spacing of Al-Cu alloys", Transactions of the Metallurgical Society of AIME, v. 239, pp. 1504-1511, 1967.

[25] KAHLWEIT, M., "On the ageing of dendrites", Scripta Metallurgica, v. 2, pp. 251-254, 1968.

[26] ROVIRA, M.M.M., Forjamento da liga AA2011 no estado semi-sólido: estudo do processo e do produto. Tese de D.Sc., FEM/UNICAMP, Campinas, SP, Brasil, 2000.

\section{ORCID}

Autor Luis Vanderlei Torres

Autor Eugênio José Zoqui
https://orcid.org/0000-0002-2249-668X

https://orcid.org/0000-0002-3614-0051 